\title{
The Research on Localized E-commerce Development of Guizhou Province
}

\author{
Min LIANG ${ }^{1, a}$ and Xiao-tian $\mathrm{LI}^{1, \mathrm{~b}}$ \\ 1 Guizhou University of finance and economics, China, Guiyang \\ aLiangmin_works@sina.com, b604329198@qq.com
}

Keywords: Localized E-commerce, O2O, Payments, Logistics.

\begin{abstract}
As all we know, the development of electronic commerce is not for a long time in China. However, it has a good trend, and the recognition and support of the government. The development of the electronic commerce has a big gap between eastern and western cities of China, as a less developed region, Guizhou still has many problems, such as poor maintenance, low usage and special natural features. This article is based on the features of Guizhou province, such as the economy, the population, the environment and so on, in order to discuss the development of electronic commerce of Guizhou, find out strategy to improve the electronic commerce development of Guizhou, especially for the minor enterprises.
\end{abstract}

\section{Introduction}

Electronic commerce work by the basic platform of computer network, using electronic and electronic technology in order to realizing the consumers online shopping, $\mathrm{O} 2 \mathrm{O}$ and online payment, this is a new business model. Comparing with the traditional business model, electronic commerce is more efficiency, convenience, openness, interactive, universality and low cost. However, there are some obvious imbalance in the development of e-commerce in China, such as developed cities and most of the eastern coastal areas are done well in e-commerce, while the less developed western regions are not so well. Guizhou is in western China, located in the western interior, neither border nor coastal, information awareness, the level of e-commerce development has lagged behind other provinces and cities. Development of Localized E-commerce is an important supplement to the economic development strategy of Guizhou, helping accelerate the process of economic and social information. This paper has analyzed about Guizhou electronic commerce development problems and find out the solutions which are very important to develop the Localized E-commerce.

\section{The Status Quo of E-Commerce Development in Guizhou Province}

In the past ten years, with the economy rapid growth and the Internet industry rapid development of China, electronic commerce enter the great development period, it can be seen as one kind of growth oriented economic model by government, enterprises and individuals. On the one hand, minor enterprises in Guizhou is in current trend of e-commerce development; on the other hand they faces the challenge of high technology intensity, large investment in $R \& D$, high risk, immature market and so on. As all mentioned above, these minor enterprises have lagged behind the development of e-commerce. The statistical data of Taobao shows that the network business is in limited quantities in Guizhou. 
As described above, to develop the localized E-commerce of Guizhou Province can effectively address the following issues. Internet transaction security issues: Localized e-commerce model supplied by way of local businesses to resolve consumer credit business to worry about. Aftermarket product quality problems caused by: in the local network transactions occur, consumers can solve related problems in a short time. Logistics is not timely, high costs and transportation time is too long cause product damage and other problems; local supply local logistics make the product the same day to get there.

\section{The Research on E-commerce Improvement Direction of Guizhou}

\section{Analysis of E-commerce Electronic Payment Methods}

Traditional E-Commerce Payment. With the continuous development of e-commerce, e-payment business is continuing to break their own, there has been appeared in a variety of electronic payment modes, with respect to the new electronic payment mode, With respect to the new electronic payment mode, the traditional e-commerce payment mode due to the longer development time and more popular. However, due to the limitations of geography and the economic development of Guizhou, resulting in network transmission of information is not timely, commodity arrival time is too long and other issues. E-commerce and high construction expenditures increased its e-commerce business risks and other factors restricting the development of e-commerce, and the store sales decreased in recent years, so the development of the localized e-commerce is the current best choice [1].

Localizede-commerce Payment. Localized e-commerce refers to the e-commerce activities within a small geographical area, this model is not suitable for long-distance transport industry, with this model E-commerce services will be localized adaptation, may also increase the conversion efficiency. $\mathrm{O} 2 \mathrm{O}$ is an important model for localized e-commerce, $\mathrm{O} 2 \mathrm{O}$. (online to offline) use of the Internet to be the foreground line transactions, the parties to the transaction can be completed via the Internet or pre-paid funds transactions, and then into the line to complete the remaining transaction Mobile devices began the integration of localization in the context of the rapid development of $\mathrm{O} 2 \mathrm{O}$, what make $\mathrm{O} 2 \mathrm{O}$ has become a major branch of localized mobile e-commerce. Localized-commerce integration of e-commerce and physical stores, it will be in two different areas of business models together, not only to make the e-commerce solution to defects in recent years, the biggest obstacle to the store encountered in development [2].

\section{Improve the E-commerce Credit Service System, Strengthen the Data Security and Information Sharing}

The government should support the credit investigation and certification, assessment institutions and intermediary organizations of e-commerce business entities to carry out network of consumer credit evaluation independently, get more docking and sharing between credit information of electronic commerce and other social field's information, crate an electronic business credit service platform for online and offline information exchange.

\section{Improve the Network Infrastructure}

Make it more meet with our province's economic and social development needs of broadband, integration, security, pan in the next generation information infrastructure construction, accelerate the upgrading of broadband networks and increases the 
bandwidth, Internet, promote the fiber to the home and overall improvement of urban and rural broadband network penetration level and access. Develop the next generation internet business, and promote the next generation o internet business become large scale in commercial use. Keep promoting the telecommunications infrastructure to build and share, make overall plan for Internet Data Center (IDC) and other cloud computation infrastructure. In summary, by localized e-commerce model can help companies flat sales channels, and reduce operating costs and improve the old model of supply chain. As shown in Figure 1 the comparison between two models.

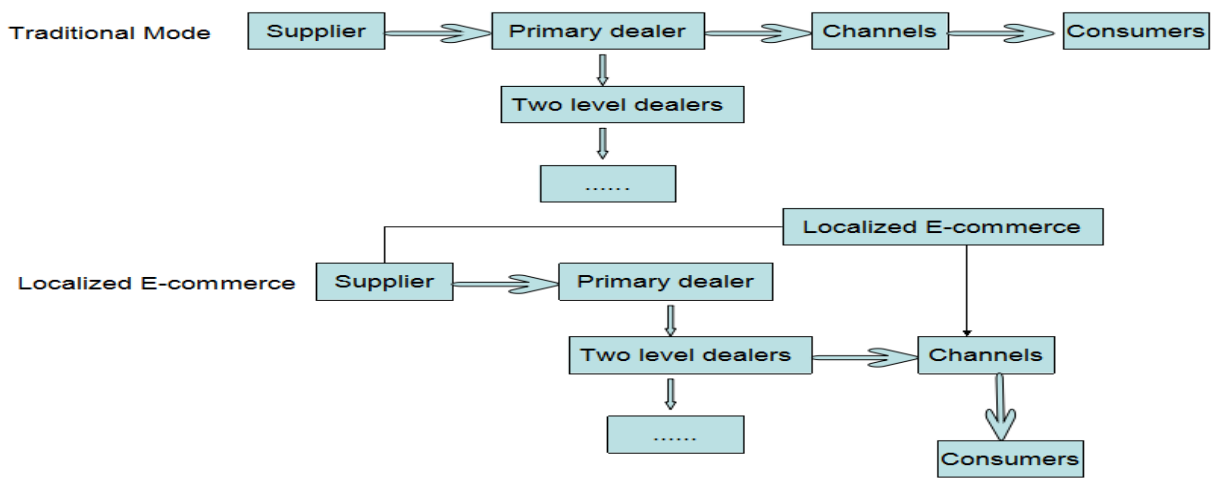

Figure1.The comparison between traditional and localized e-commerce

\section{Specific Implementation Strategies in Guizhou Province's Localized E-commerce Development}

\section{Establish the Demonstration Project of E-Commerce}

(1)Speed up the constructions of the e-commerce demonstration cities. Emphasize on the cities and states with mature conditions to establish national mobile e-commerce service demonstration city, wireless smart city and national e-commerce demonstration city. Elevate the cities' comprehensive e-commerce application level and industry scale, and then radiate towards around adjacent areas.

(2) Vigorous push forward the construction of the e-commerce base. Encourage all local governments and large-scale enterprises build e-commerce base. Focus on supporting those main industrial parks and ethnic trade counties to apply to establish national and provincial e-commerce bases. Speed up the establishment of well-known e-commerce congregation locations, which will combine various factors, such as the local features, research, design and supporting service. Focus on establishing a bunch of e-commerce start-up parks, which will be the incubators for the medium or small-scale businesses.

(3) Vigorously nurture and bring in key leading enterprises. Focus on nurturing national and provincial demonstration enterprises, make effort to build a number of e-commerce enterprises that will have considerable scales and domestic and oversee influence. Try to bring in a bunch of key leading enterprises which will possess the following advantages: cutting-edge technology, renovated models, large-scale markets, strong ability to reconstruct resources, and vast radiation capability. And attract large-scale enterprises set up their headquarters, tech-innovation center, service center and operation center in Guizhou.

\section{Strengthen the Policy Support}

(1) Strengthen the financial support. Take advantage of the central and provincial government's financial preferential policy, in the forms of rewards and lower load 
rates, to support e-commerce's scientific research, model innovation, study-production-transformation, application in medium and small enterprises, fund-raising for medium and small enterprises, information service for the rural areas, e-commerce service for the public. Support the upgrades of the e-commerce enterprises in our province and bring up a bunch top-class e-commerce brands. For the famous newly brought-in enterprises, if they set $u$ their (regional) headquarters in Guizhou, the local government can give a one-time reward, funded by the local government. Encourage the local government to set aside specific fund and work out relevant rewards policy to support the e-commerce development.

(2) Strengthen the support in land allocation. Any cities above the regional level should prioritize the land demands of the e-commerce enterprises' expansion, the settlement of the e-commerce settlement home and abroad, and the massive e-commerce project. On the condition that the overall land allocation planning is in accordance with the urban and rural planning, places such as empty factories and warehouse should be encouraged to develop into e-commerce parks. The usage doesn't have to alter right away if the main frame of the land stays unchanged without reconstructing.

(3) Lower the threshold of business registration. Lower the minimum monetary requirement for e-commerce registration. Create new measures of registration. Lower the criterion for e-commerce enterprises to enter the market and allow them to explore new models of e-commerce operation before registration (which can be post-registered), give these enterprises permission to be registered as "e-commerce" companies [3].

\section{The Furthering and Popularity of E-commerce Applications}

Cultivate a batch of e-commerce platform of Guizhou characteristics products. Relying on the "five 100 project" strategy to construct ecommerce platform; Promote the traditional trade change into modern trade. Constructs E-mall vigorously for selling Guizhou's characteristic products, strengthen and vocation and improve the product pre-sale and after-sale service content, expand business scale and visibility. Introduce and support large e-commerce platform and set up operations center, procurement and logistics base, branches, such as customer service center, set up regional e-commerce platform, provides the high quality service and quick trading channels, in order to promote the economic rising of our province [4].

Guide traditional trade and exchange businesses to develop e-commerce. Support should be granted to the enterprises in these businesses to strengthen the application of the e-commerce by developing, co-investing or cooperation with others. And we shall also support tradition malls and supermarkets to start their retail business online, while based on their original business resources such as their physical stores, commodity supply and delivery system; support them to the o2o business models such as "checking samples online and fetch goods off line", " order online and consume offline". Enhance the cyber consumption of the dinning, hospitality, rural restaurants, beauty salons and entertainment etc. Encourage large-and-medium-scale whole sellers to extend their sales, counseling and purchases and other business activities based on the e-commerce platforms, so their resources can be fully exploited and their competition capability can be elevated.

Develop e-commerce applications. Promoting e-commerce apply to education, health, logistics, culture, exhibition, services, digital publishing, community service, domestic service areas, develop the online exhibition, electronic tourism, network education, online hospital, online market, community e-commerce and so on[5]. 


\section{Encouraging the Development of E-commerce Services}

Encourage the development of trading services platform, technical service platform, and intermediary service platform for local independent e-commerce, cultivate a group of influential industry, providing electronic business consulting, marketing, information, law, information technology and human resources professional service of electronic business service enterprise. Support the e-commerce service web sites, which are in large scale, influential and in line of market demand, actively promote the high added value of e-commerce in derivatives of development and application [6].

Support e-commerce service enterprises (including the third party electronic commerce platform, financing guarantee, all kinds of services such as logistics distribution enterprise) using the go global strategy ,establish overseas service, warehousing logistics, customer service system construction, form section of strategy partner relations with overseas e-commerce service enterprises, etc.; Support local e-commerce enterprises set up overseas marketing channel mode, compression channel cost, create own brand; Accelerate the construction of Guiyang comprehensive bonded zone, establish and improve infrastructure, guide enterprises to fender and garrison, and produce ,make full use of bonded processing, bonded warehouse, bonded logistics and bonded display, in order to operate the cross-border trades[7].

\section{Conclusions and Next Steps}

Localization of e-commerce is a business model based on services for life. it's an innovative e-commerce business model. Based on theory and localization of e-commerce service life theory summarized, next work is to analyze existing typical electronic commerce platforms, according to the actual needs of small and medium enterprises in Guizhou, to build online business store for enterprise. By these stores, increase business in the development process more complete information industry chain, make Guizhou enterprises solve the problem of Website promotion and online sales.

\section{Acknowledgement}

This research was financially supported by Software Science Project of Guizhou: R [2012] LKC2002.

\section{References}

[1] Min A,Ji S. A Meta. Analysis of mobile commerce research in China (2002-2006)[J]. Int.J. Mobile communications, 2008, 6(3).

[2] Zorayda Ruth Andam E-Commerce and E-Business[M] Manila, Philippines: e-ASEAN Task Force,2013.

[3] NGAI EWT, GUNASEKARAN A. A review for mobile commerce research and applications [J]. Decision Support Systems, 2007, (1): 3-15.

[4] Upkar Varshney. Business Models for Mobile Commerce Services: Requirements Designand the Future, IT Pro November/December 2008:48-55. 
[5] Norman Sadeh. M-Commerce: technologies, services, and business models. USA: Wiley Computerpubhshing, 2012.

[6] RFC2527: Internet X.509 Publie Key Infrastrueture: Certifieate Poliey and Certifieatio Practices Framework.

[7] MIC.U-Korea Master Plan[R].Ministry of Information and Communication in Korea, 2014. 